\title{
Alpe Adria report 2010 - conclusions and recommendations for the treatment of alcohol dependence
}

\section{Dagmar Kogoj' *, Giovanni Addolorato ${ }^{2}$, Anna Ferrulli2, lannis Mouzas 3 , Lubomir Okruhlica4, Flavio Antonio Poldrugo ${ }^{5}$, Golda Schlaff', Tomáš Zima ${ }^{6}$, Otto Lesch ${ }^{1}$ and Henriette Walter ${ }^{1}$}

\author{
Department of Psychiatry and Psychotherapy, Medical University Vienna, Vienna, Austria \\ 2 Department of Internal Medicine, Catholic University of Rome, Rome, Italy \\ ${ }^{3}$ Department of Gastroenterology, University Hospital of Heraklion, Heraklion, Greece \\ ${ }^{4}$ Centre for Treatment of Drug Dependencies, Bratislava, Slovakia \\ ${ }^{5}$ Department of Psychiatry, School of Medicine University of Trieste, Trieste, Italy \\ ${ }^{6}$ Institute of Clinical Chemistry and Laboratory Diagnostic, Charles University Prague, Prague, Czech Republic \\ *Correspondence: dagmar.kogoj@meduniwien.ac.at
}

\section{INTRODUCTION}

At the ninth Alpe Adria convention, which took place between the 27 and 29th of May 2010 in Villach/Austria, experts from different European countries (namely Italy, Bulgaria, Serbia, Slovakia, Czech Republic, Greece, Slovenia, Croatia, and Austria) discussed the epidemiology, available treatment concepts, and research methods used in alcohol-dependent patients in their countries. Representatives of five of the participating countries decided to present recommendations and treatment approaches in alcohol-dependent patients, agreeing to avoid the establishment of general guidelines.

\section{EPIDEMIOLOGY}

Based on European and American epidemiological studies, approximately $8.5 \%$ of the population suffers from alcohol use disorders (abuse and dependence, according ICD-10; NIAAA, 2008).

In 2008, the National Institute on Alcohol Abuse and Alcoholism presented a cross-sectional report, stating that in most countries the estimated percentage of the population fulfilling the criteria of alcohol dependence according to the ICD-10 and DSM-IV criteria is at approximately $4 \%$ (NIAAA, 2008).

At our meeting, several countries were not able to show representative data. However, the available data showed significant differences in the rates of alcohol use and dependence.

According to the Statistical Institute, the spread of alcohol consumption in Italy had been stable over the past 10 years (about $70 \%$ of general population), but over time, the consumer behavior has begun to change significantly (ISTAT, 2010). In particular, drinking patterns similar to those observed in northern Europe, where the consumption of alcohol is mainly apart from meals, is emerging. Over the last 30 years, a lower consumption of wine has been observed, while the consumption of spirits and beer maintained constant and slightly increased, respectively. In 2009, a survey of the Italian population over the age of 11 years had been conducted and yielded the following results: $68.5 \%(n=36,549,000$ people) were reported to have been drinking alcohol in the previous 12 months; $27 \%$ $(n=14,419,000)$ consumed at least one type of alcoholic beverage on a daily basis; $15.8 \%$ $(n=8,454,000)$ were identified as hazardous drinkers (heavy drinkers or binge drinkers). According to the database of the European Health for All (WHO, 2010), the per capita alcohol consumption in Italy is $10.45 \mathrm{l}$ /year, which is well above the WHO recommendation targets for 2015 (6 l/capita/year). In particular, an increase by 1.8 percentage points in the percentage of women aged 19-64 years who consume wine or alcoholic beverages outside meals has been recorded with respect to 2003 data. In 2006, 61,656 alcohol-dependent patients (48,324 males and 13,332 females), who have been followed by more than 400 working groups distributed over the country, have been recorded in Italy (WHO, 2010).

The incidence of alcohol dependence is about 5000 new cases/year (Scafato, 2008) and the percentage of alcohol dependence among young people is increasing. Specifically, the strongest growth over time is noted in the 20-29 age group compared to other age groups - from $10.7 \%$ in 1998 to $14 \%$ in 2004 . Actually, $15 \%$ of the Italian alcohol-dependent patients are under 30 years of age. (Scafato, 2008).
According to EPIAF study (trans-sectional survey), in the year 2004, approximately 300,000 people with alcohol-related problems were detected in the Slovak Republic, which accounts for about 5.5\% of the country's inhabitants (Heretik et al., 2008).

In the Czech Republic, the consumption of alcohol fluctuates at $10 \mathrm{l} /$ capita/year and shows a slowly increasing trend (NMSAT, 2010). In the population of 16 year old adolescents, the prevalence of binge drinkers in the past 12 months was found to be at $48 \%$, the combination of alcohol with medications at 18\% (Hibell et al., 2009). Binge drinking is a continually increasing trend. In 2007, the Czech Republic had the highest prevalence in the indicator of drunkenness in last 12 month. Forty-eight percent of 16 year old adolescents had experienced drunkenness at least once, which is $9 \%$ over the EU-average. This trend has specifically increased in the female population (Csémy et al., 2006, 2009). In general, we have only little insight into the alcohol consumption habits of the general population. According to recent estimations, 450,000 people in the Czech Republic misuse alcohol, which accounts for $0.4 \%$ of the total population (Sovinova and Csémy, 2010).

Another study has published data showing that approximately $1,300,000$ people demonstrate risk patterns of alcohol consumption, whereas the prevalence of alcohol dependence is at $7.2 \%$ of the Czech adult population (aged 18-64). The alcohol consumption among men is higher when compared to women. The highest alcohol consumption has been observed among men aged 35-64 years. While younger people consume alcohol less often, however in higher amounts, the older ones prefer to 
consume alcohol on a regular basis, however in lower amounts. The most frequently consumed type of alcoholic beverage was beer among men and wine among women. Fridays and Saturdays were days associated with the highest rates of alcohol consumption. If compared to the 2002 survey, the alcohol consumption among respondents slightly increased (Kubićka and Csémy, 2004).

According to the, WHO (2002) $42.5 \%$ of the Greek male population and $13.6 \%$ of the females consume alcohol daily.

The data from a study performed in a representative sample of the Attica region population (1,514 adult men and 1,528 women) shows, that the daily consumption of pure alcohol (in grams) is $225( \pm 45)$ among men and $95( \pm 39)$ among women (Pitsavos et al., 2003).

\section{ALCOHOL AND ITS BURDEN ON SOCIETY}

Based on scientific literature, we have agreed that alcohol dependence must be understood as a chronic disease with various forms of relapses (with and without loss of control) and as one of the leading causes of preventable deaths in the European Union (European Commission, 2006) seen as a major public health hazard, all countries agreed that improved methods of prevention, diagnosis, and treatment of alcohol use disorders are essential and necessary.

For example, in Italy, at least 24,000 deaths/year occur due to the effects of alcohol (Scafato, 2008). Alcohol use contributes to a range of acute and chronic health consequences, ranging from injuries resulting from traffic accidents to carcinomas, and cardiovascular diseases. It has been estimated that $5.31 \%$ of all male and $3.01 \%$ of all female cancer diagnoses are alcohol attributable; $5.74 \%$ of all male and $2.19 \%$ of all female deaths resulting from a cardiovascular disease are alcoholrelated; alcohol-related deaths from liver cirrhosis are $47.75 \%$ in males and $40.03 \%$ in females; alcohol-related deaths from injuries are $26.25 \%$ in males and $11.37 \%$ in females. Finally, of all deaths, the total alcohol-related deaths are at $6.23 \%$ in males and $2.45 \%$ in females (Rehm and Scafato, 2011).

Moreover, 108,000 hospitalizations are wholly attributable to adverse effects of binge drinking and the percentage of alcohol-dependents using assessment, treatment, and rehabilitation services increased by $108 \%$ in the past 10 years. In Italy, in 2006, the number of alcoholrelated hospital admissions was 102,367 (77.5\% males, $22.5 \%$ females). The main diagnosis of admission was alcoholic liver cirrhosis (32.9\%; Italian Ministry of Health, 2009).

Alcohol plays a major role in many fatal road accidents. In Italy, alcohol is the cause of nearly $50 \%$ of deaths due to road accidents and is also the leading cause of deaths in men under the age 40 .

Consequently, alcohol consumption imposes a marked economic burden on society in several aspects including health care costs, costs of productivity loss, costs of property damage, costs of criminal justice, and law enforcement, etc. Furthermore, it has been found that this impact does not only affect individual drinkers, but also non-drinkers who live in the same society. It was estimated that in Italy 3\% of the GDP (Gross Domestic Product) is attributable to adverse effects of alcohol.

While in most EU countries cardiovascular and cancer mortalities are decreasing, in Slovakia, they are still the leading cause of death, without showing any significant signs of a decline in the last decade. This is mostly attributed to the unhealthy life-styles of the inhabitants, influenced by factors such as high alcohol and tobacco consumption.

In the Czech Republic, traffic participants, who have died as a consequence of a road accident, were tested for their alcohol blood level. About $29.2 \%$ of the drivers and $51.8 \%$ of the pedestrians tested positive for alcohol (Mravčíkv et al., 2009). In the year 2009, 123 persons were killed by traf- fic accidents connected with alcohol consumption (Czech Ministry of Transport, 2010).

At the psychiatric institutions/wards in the Czech Republic, 15,336 cases of hospitalization with the main diagnosis ranging from F10-F19 have been recorded, of which 10,026 patients were diagnosed with F10 (Mravč́kv et al., 2009).

Also, in Greece, the use and misuse of alcohol has increased alarmingly. However, this fact has not yet received adequate social or state attention. It seems that heavy alcohol consumption has been integrated into modern life-style and, generally, is not considered to be an antisocial activity. In rural areas, the daily consumption of alcohol in places of social interaction (cafés, taverns, bars) is more than common, as well as intermittent heavy use at social events (local religious celebrations, feasts, wedding, or birthday parties). In urban areas, daily consumption is neither that prominent nor extended. Nevertheless, binge drinking has emerged where it was unknown before and the number of youth and adolescents that are exposed to binge drinking is rising.

Following data on standardized mortality-rates (per 100,000) for acute and chronic disease and injury are relevant: falls 3.2, intended injuries 4.1, traffic accidents 18.9 , poisoning 2.6 , alcoholic disease 0.1 , liver cirrhosis 3.8 , cancer of mouth and pharynx 1.2, ischemic heart disease 63.7 (WHO, 2004). According to the data from the National Statistic Office, alcohol-related road accidents were 216.1/100,000 inhabitants in the year 2000 and 185.5 in 2001.

\section{DIAGNOSIS OF ALCOHOL DEPENDENCE}

To objectivize alcohol intake the following biological markers are used:

\begin{tabular}{|c|c|c|c|}
\hline & Sensitivity & Specificity & Normalization in abstinence \\
\hline Breath alcohol & $100 \%$ & $100 \%$ & Hours \\
\hline Ethyl glucuronide & $100 \%$ & $100 \%$ & Days \\
\hline $\mathrm{MCV}$ and $\gamma-\mathrm{GT}$ & $63 \%$ & $80 \%$ & 1-10Weeks \\
\hline$\%$ CDT & $65 \%$ & $96 \%$ & 2-4 Weeks \\
\hline \multicolumn{4}{|c|}{ CUT - OFF - POINTS } \\
\hline GOT > GPT & \multicolumn{3}{|c|}{ Alcohol-toxic liver damage very likely } \\
\hline $\mathrm{GPT}>\mathrm{GOT}$ & \multicolumn{3}{|c|}{ Liver damage varying in origin } \\
\hline$\gamma-\mathrm{GT}$ & \multicolumn{3}{|c|}{$\begin{array}{l}\text { An increase to } 1.3 \text { times the upper limit of standard value speaks for } \\
\text { alcohol-toxic liver damage }\end{array}$} \\
\hline MCV & \multicolumn{3}{|c|}{ >95 fl: alcohol misuse can be suspected } \\
\hline$\%$ CDT & \multicolumn{3}{|c|}{$>2.6 \%$ speaks for alcohol-toxic liver damage } \\
\hline
\end{tabular}


Twin and adoption studies have shown that in more than $50 \%$ of the cases a genetic burden exists (Koehnke, 2008). The heterogeneity of the disease is undoubted and empirically supported, as presented in a study by Hesselbrock and Hesselbrock (2006), where clinically useful subtypes of alcohol dependence are defined.

The characteristics of a useful classification system should be comprehensiveness and specificity, heterogeneity between the groups, stability, and multidimensionality and of course they should be easily used in clinical work.

Today four or five subgroups seem to be established for diagnosis, prognosis, and special therapy.

High alcohol intake, severe craving, and severe withdrawal define one type. Another one is mainly defined by a mildly affected long-term course. The third is accompanied with psychiatric comorbidities, the fourth one with an antisocial long-term course. Authors in Portugal and other southern European countries are of the opinion, that there should be a separate group containing early multiple drug dependence (Pombo and Lesch, 2009).

In Italy, alcohol dependence is widely diagnosed by the criteria of DSM-IV. Interviews and self-report questionnaires could be useful to assess quantity and frequency of drinking. Questions focus on two principal aspects: consequences of drinking and perceptions of drinking behavior. The CAGE questionnaire- the name is composed as an acronym of its four questionsis commonly used to determine the risk of alcohol-related problems. The alcohol use disorders identification test (AUDIT), a screening questionnaire developed by the World Health Organization has been validated in six countries and is used internationally. Like the CAGE questionnaire, it uses a simple set of questions - a high score earning a deeper investigation.

In order to measure craving, simple scales such as the visual analog scale (VAS) have been applied. However, methods have recently been developed, which provide a less subjective measurement, consisting of self-administered questionnaires that evaluate the obsessive-compulsive behavior toward alcohol: obsessive-compulsive drinking scale (OCDS), alcohol urge questionnaire (AUQ), Penn alcohol craving scale (PACS), etc.
In Slovakia the ICD-10 criteria are widely used to diagnose alcohol-related problems and there is no common use of characteristics leading into the classification into subtypes.

Despite continues discussions about different clinical perspectives and therapeutic approaches for patients with special needs, in the Czech Republic no specific research projects and publications in this area are present.

Also, in Greece, no subtypes of alcohol dependence, such as Barbor or Lesch etc., are in common use. Two main diagnostic types have been established: alcoholism with and alcoholism without a psychiatric comorbidity.

In Austria, the Lesch typology is being introduced (Figure 1), and depending on one of the four subtypes, special programs are offered. However, in most centers in Austria the heterogenic categorization of alcohol-dependent patients into subtypes is not standard procedure. As a consequence, patients are not offered individual and personalized treatments, but instead are all treated in the same manner, often leading to unsatisfactory results. Some of them are dominated by psychotherapeutic approaches ("nothing over the lips"), while others are solely pharmaceutically driven treatment approaches (Lesch et al., 2011).

\section{COUNSELING, TREATMENT, AND LONG-TERM GUIDANCE OF ALCOHOL- DEPENDENT PATIENTS}

All countries agreed that the best treatment for alcohol dependence is early recognition and intervention, best starting before the onset of alcohol intake. The prevention of intoxication during pregnancy (alcohol and tobacco) should be a main target of the public health system. Information and special programs for young people have proven to be effective; special attention should be turned on young people under difficult social conditions, e.g., not loved by parents, frequent altering of caregivers, problems with social integration, binge drinking leading to hospitalization, delinquency, etc.

The focus of health systems on early detection in medical settings should be achieved in order to prevent further disease progression. Currently, the approximate time needed for medical disabilities, which he clearly been caused by alcohol, to receive special alcohol treatment, is 7 years.

The sourcing of treatments strongly varies in the individual countries and also influences the availability of treatment programs. Family approaches as well as internal medicine based treatments are available in Southern Europe, while psychiatric treatments and Alcoholics

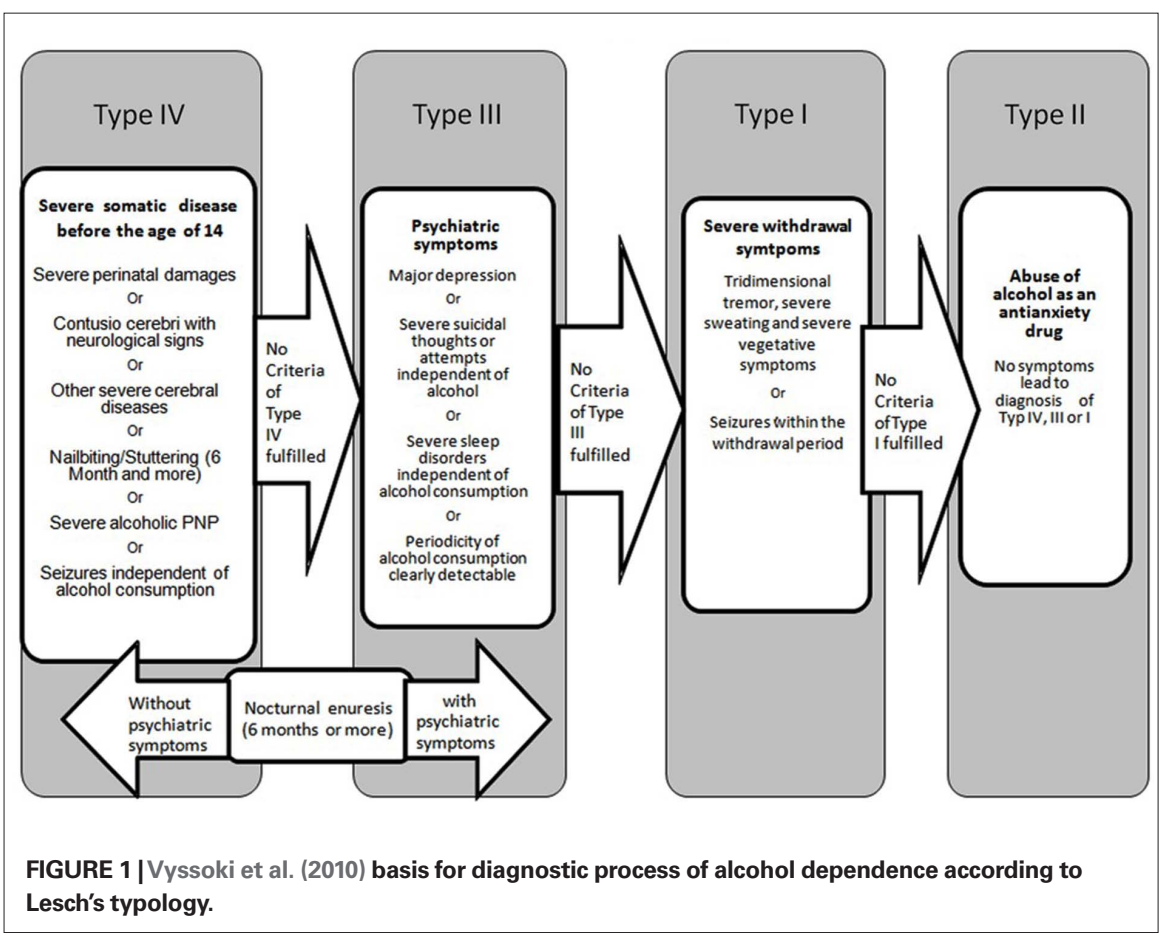


Anonymous (better known as AA-groups) have been established in the northern countries. Motivational interviewing as a first step of treatment is globally used because one of the core-symptoms of addiction is the missing motivation for changing life-style and alcohol intake (Miller et al., 2003).

In Italy, treatment is mainly initiated in public hospitals with more than 200 alcohol units. Long-term follow-up is then covered by an extended program that is represented by the Clubs of Alcoholics under Treatment, which implies an integrated family and community approach, and is affiliated to the public health services. AA-groups follow in number, but other private and public initiatives exist.

In addition to psychosocial treatment, in Italy, pharmacotherapy is used in several addiction units. Pharmacological treatment of patients affected by alcohol abuse and alcoholism is an emerging mean of enhancing alcohol-abstinence and preventing relapse, complementing psychosocial interventions that have been used for many years. Specifically, craving has became a very important target for the treatment of patients with alcohol problems and several drugs, able to interfere with the neurotransmitters involved in craving mechanisms, have been proved. One of the first drugs approved for the treatment of alcoholism and currently in use in Italy is Disulfiram. Although Disulfiram's mechanism of action in alcohol dependence was long thought to be its effects as a psychological deterrent, more recent studies have uncovered potential anti-craving effects (Barth and Malcom, 2010). Further, Acamprosate and Naltrexone have been established for the use in relapse prevention treatment, while Baclofen is used as an off-label drug (Addolorato et al., 2007, 2009; Addolorato and Leggio, 2010).

In Italy and increasingly also in Austria, Gamma-hydroxybutyric acid is used for the treatment of alcohol dependence, and that it has been shown to be effective both in reducing alcohol consumption and withdrawal symptoms both in animals and in humans (Gessa et al., 2000). In particular in alcoholics GHB have shown its ability to suppress the alcohol withdrawal syndrome with an efficacy similar to that of diazepam and chlormethiazole and to prevent alcohol relapse (Addolorato et al., 2009).
Pharmacological therapy should not be considered as the only form of treatment, but as an integrated part of a multi-modal approach including psychological and social support; moreover successful detoxification represents an important element, improving motivation for further treatment and preventing relapse (Addolorato et al., 2005a,b).

Today in Slovakia the attention is paid to general and selective primary prevention of alcohol-related problems. The Ministry of Education and the whole sector of education play a leading role in the field of prevention within the National Program on problems with alcohol. A bio-psychosocial approach is based on a biological model of alcohol dependence and alcoholrelated harms. Consequently, the treatment interventions are complex programs with pharmacological, psychotherapeutic, and social components. Acamprosate is the most common medication for relapse prevention. Naltrexone is not registered. Disulfiram is not used any longer in Slovakia. Special attention is paid to physical comorbidity, such as gastroenterological and cardiovascular diseases, as well as to neurological complications. Thiamine is part of standard treatment. After the treatment of acute alcohol withdrawal, mostly medicated with diazepam, the cognitive behavioral therapy (CBT) and motivation-enhancement therapy are two generally accepted and applied psychotherapeutic approaches. Patients have the choice between a variety of different treatment options: combinations with continuation in in-/out-patient programs, individual and/or group therapy, brief intervention with counseling, or full treatment, which lasts for 12 months in best cases. Non-medical social aftercare may follow. In Slovakia, health care is primarily abstinenceoriented. The harm-reduction approach is prevalent in patients with frequent relapses, or in chronic excessive courses of drinking. Alternative, non-medical treatments are marginal in their significance (e.g., AA, spiritual treatment). But, however, most of the people with alcohol-related problems are still untreated, since they do not seek treatment. Treatment is fully covered by health insurance and is free of charge. The main barriers preventing people from entering the treatment programs are the prejudices found in the general population, but also among the health staff (IATPAD, 2009).
In the Czech Republic the core of the treatment system lies in psychiatric hospitals with special units for addicted persons. There are 16 psychiatric hospitals with this type of special care (long-term treatment from 8 to 12 weeks) and 32 psychiatric departments in hospitals where it is also possible to treat addictions (Mravčíkv et al., 2009).

A lack of out-patient treatment systems exists. There are 357 providers across the Czech Republic, which treat more than 15,000 addicts/year (with a minimum of 1 visit/year), including illegal drugs abusers. However, there is no data about alcohol user subgroup in this population. AA-groups have a relatively long tradition (Gabrhelík and Miovskú, 2009), but there are more models of self-help groups usually in connection (and support) with the staff of psychiatric hospitals. There is still an absence of special care for patients with comorbidity and special needs. On the other hand there are several special hospitals (e.g., Apolinar in Prague, Cerveny Dvur, or Bíla Voda), where alcohol-dependent patients are in joint treatment programs. This approach has been cultivated for many years with positive experiences. There are several programs for subsequent aftercare, yet this is not typical.

In Greece, the following services exist: five established therapeutic programs that offer specialized services for alcoholics; two specialized structures in general hospitals; six addiction programs that offer parallel treatment to alcoholics; and two mutualhelp based intervention structures. The treatment approaches vary, but, in general, the aims of the therapy are alcohol-abstinence, improvement of psychosocial functions, commitment to therapy, and relapse prevention.

The therapeutic frameworks are:

- Out-patient treatment: advised for patients that have the ability of selfcare, have strong motivation, and a supportive family and social network.

- Inpatient treatment: advised for patients that have a special need for strict structures, support, security, and whose environment, family or social, may be either supportive or negative or high risky. It is about a framework of intensive care. 
The theoretic models of therapeutic approach for both individual and group therapy may include motivational interviewing, cognitive-behavioral approach as well as psychodynamic and family therapy.

Treatment programs include psychotherapy, in the beginning individual therapy and later on psychotherapeutic group therapy, in addition to a pharmaceutical regimen, if needed, and at the same time therapeutic intervention in the form of family therapy.

Pharmaceutical therapy, after the phase of somatic detoxification, includes Naltrexone, Acamprosate, and specific psycho-pharmaceutical treatment as needed in comorbidity cases.

In Austria in- and out-patient treatment is paid by the health insurances. For people, who are not insured, the municipalities bear the costs. Most of the patients are treated by the social services or at the general practitioner. Only $4 \%$ of alcoholdependent patients are treated in specialized out- and in-patient alcohol units. Only $1.4 \%$ is treated in institutions with longterm treatment programs (6-8 weeks). The Lesch typology, which classifies alcoholdependent persons into four subtypes, is used as a guideline for determining the medical treatment, psychotherapeutic approaches as well as socio-pedagogical work necessary for the patients (Lesch et al., 2011). Prospective studies using these approaches show significantly better outcomes than uniformed treatment concepts. The Lesch alcohol typology computer program has recently been translated into most of the European languages and has started to be become used in daily practice (e.g., Bulgaria, Greece, Poland etc.). Academic knowledge shows us, that the combination of psychotherapeutic approaches with pharmaceutical treatments is essential to long lasting abstinence. However, social support is also a crucial element of the treatment plan. Without social support, even the best the treatment may be useless (e.g., homeless, people living in poverty, isolated people in fringe groups, refugees, asylum seekers etc.; Lesch et al., 2011).

\section{OUT-COME CRITERIA}

In most of the countries absolute abstinence is still the only accepted goal. In many long-term studies it has been shown, that only approximately $15 \%$ of patients can reach this idealistic goal. Today, the growth of sobriety and reduction of alcohol intake (amount and duration) are accepted goals of treatment (EMA, 2010; Lesch et al., 2011). In severe alcohol-dependent patients with severe alcohol-related disabilities (Type IV patients according to Lesch), the decrease of mortality-rates is often the only possible goal. Therefore, the objective in such cases should be careful guidance, offering a structured daily routine, social support, and environment, in combination with leisure facilities.

The principal objectives of the Italian National Health Service are as follows:

- Greater knowledge and awareness of alcohol harm in the general population.

- Reducing deaths, injuries, or number of accidents, especially among young people.

- Reducing workplace accidents and violence.

- Treatment of alcohol abuse and alcohol dependence.

- Increasing the responsibility of alcohol producers and distributors.

- Supporting organizations that promote prevention initiatives and alcohol-related harm reduction.

- Monitoring alcohol-related harm (Italian Ministry of Health, 2010).

In accordance with Mclellan (2010), in Slovakia, alcohol-related mental disorders, including dependence, are viewed as a spectrum of different courses with different intensities. Long-term abstinence, or even controlled drinking in some cases, are favorable outcomes. However, chronic relapsing with different trajectories is typical for most of the patients. Reducing harm and extension of lives are often the main objectives, consistent with the goals in other medical disciplines treating chronic diseases. This point of view is resembles the assessment of the outcomes based on Lesch's typology. So far, no solid system or protocol for the evaluation of treatment outcomes of alcohol-related mental disorders is available in Slovakia.

In the Czech Republic, there are continuous discussions on the outcome criteria and goals in the treatment of alcohol dependence (from the traditional goal of "persistent and consistent abstinence" to the more modern goal of "quality of life"). Since 2005, at the Annual National Conference on Addictions, panel discussions, and workshops dealing with this topic, have become the routine.

\section{CONCLUSION}

1 A differentiation between alcohol abuse und dependence is the first step for further treatment. To avoid further damage to health, such as liver disease, the WHO recommends, to reduce alcohol drinking under the limit of risk ( $<40 \mathrm{mg}$ /day for men and $<20 \mathrm{mg} /$ day for women). To achieve this, the dependence on alcohol must be seen as a heterogenic brain disease with significant medical and social consequences.

2 Relapses should be seen as a part of the chronic disease, alcohol dependence.

3 Today four different subgroups of alcohol dependency have been defined and established for treatment and research.

4 A lack of motivation to stop drinking alcohol should be seen as a key symptom of alcohol dependency.

5 There should be more discussion about prevention.

Defining the subgroup, collecting biological markers and gathering data on psychological/social conditions can create an individual treatment concept.

Of course governmental institutions must pay the treatment programs, including medical treatment, psychotherapy, and social projects.

The various countries have focused on the different treatment fields, of which all deserve appropriate attention. By exchanging experiences we have observed different and enriching admissions and backgrounds.

The various approaches, whether of medical, psychotherapeutic, or of social origin, must not be seen as contradictions, but should instead compliment each other.

If such an approach could be established, early professional treatment could be implemented, followed by better outcomes in the population's drinking behavior, whereas alcohol-related consequence could be avoided more easily and the high death rates in this group of patients could be lowered significantly. 


\section{REFERENCES}

Addolorato, G., and Leggio, L. (2010). Safety and efficacy of baclofen in the treatment of alcohol-dependent patients. Curr. Pharm. Des. 16, 2113-2117.

Addolorato, G., Leggio, L., Abenavoli, L., Caputo, F., and Gasbarrini, G. (2005a). Baclofen for outpatient treatment of alcohol withdrawal syndrome. J. Fam. Pract. 54, 24.

Addolorato, G., Leggio, L., Abenavoli, L., and Gasbarrini, G. (2005b). Neurobiochemical and clinical aspects of craving in alcohol addiction: a review. Alcoholism Treatment Study Group. Addict. Behav. 30, 1209-1224.

Addolorato, G., Leggio, L., Ferrulli, A., Caputo, F., and Gasbarrini, A. (2009). The therapeutic potential of gamma-hydroxybutyric acid for alcohol dependence: balancing the risks and benefits. A focus on clinical data. Expert Opin. Investig. Drugs 18, 675-686.

Addolorato, G., Leggio, L., Ferrulli, A., Cardone, S., Vonghia, L., Mirijello, A., Abenavoli, L., D’angelo, C., Caputo, F., Zambon, A., Haber, P. S., and Gasbarrini, G. (2007). Effectiveness and safety of baclofen for maintenance of alcohol abstinence in alcohol-dependent patients with liver cirrhosis: randomised, double-blind controlled study. Lancet 370, 1915-1922.

Barth, K. S., and Malcom, R. J. (2010). Disulfiram: an old therapeutic with new applications. CNS Neurol. Disord. Drug Targets 9, 5-12.

Csémy, L., Chomynová, P., and Sadílek, P., Evropskáškolnístudie o alkoholu a jiných drogách (ESPAD). (2009). Výsledkypr uzkumu vĆeské republice vroce 2007. Praha: Úrad vlády ćeské republiky.

Csémy, L, Lejčková, P., Sadílek, P., and Sovinová, H., Evropskáškolnístudie o alkoholu a jiných drogách (ESPAD). (2006). Výsledky pr ${ }^{\circ} u z k u m u$ vĆeské republice vroce 2003. Praha: Úrad vlády ćeské republiky.

Czech Ministry of Transport. (2010). Road Traffic Accidents Caused Under Influence of Alcohol in the Czech Republic in 2009 [Online Database]. Available at: www.ibesip.cz/979_Road- Traffic-AccidentsCaused-Under-Influence-of-Alcohol-in-the-CzechRepublic-in-2009 [accessed 29.09.2011]

EMA. (2010). Guideline on the Development of Medicinal Products for the Treatment of AlcoholDependence [Online Database]. Available at: http://www.ema.europa.eu/ docs/en_GB/document_library/Scientific_guideline/2010/03/WC500074898.pdf [accessed 01.03.2011].

European Commission. (2006). Alcohol-Related Harm in the EU, Key Data, [Online Database]. Available at: http://ec.europa.eu/health/archive/ph_determinants/ life_style/alcohol/documents/alcohol_factsheet en.pdf [accessed 29.09.2011].

Gabrhelík, R., and Miovský, M. (2009). History of self-help and 'quasi-self-help' groups in the Czech Republic: development and current situation in the institutional context of drug services. J. Groups Addict. Recover. 4, 137-158.

Gessa, G. L., Agabio, R., Carai, M. A., Lobina, C., Pani, M., Reali, R., and Colombo, G. (2000). Mechanism of the antialcohol effect of gamma-hydroxybutyric acid. Alcohol 20, 271-276.
Heretik, A. Jr., Heretik, A. Sj., Novotný, V., Ritomský, A., Pečeňák, J. (2008). Epiaf: Epidemiológia alkoholizmu a fajčenia na Slovensku. NovéZámky: Psychoprof.

Hesselbrock, V. M., and Hesselbrock, M. N. (2006). Are there empirically supported and clinically useful subtypes of alcohol dependence? Addiction 101, 97-103.

Hibell, B., Guttormosson, U., Ahlstrom, S., Balakireva, O. Bjarnasson, T., Kokkevi, A., and Kraus, L. (2009). The 2007 ESPAD Report: Substance Use among Students in 35 European Countries. Stockholm: The Swedish Council for Information on Alcohol and Other Drugs. IATPAD. (2009). IATPAD Project 2009. Available at: http:// ec.europa.eu/health/alcohol/docs/ev_20100914_ co13_en.pdf [accessed 01.03.2011].

ISTAT (2010). L'uso e l'abuso di alcol in Italia. [Online Database]. Rome, Istituto nazionale di statistica

Italian Ministry of Health. (2010). Dipartimento della prevenzione e della comunicazione direzione generale della prevenzione sanitaria-ufficio VII, Relazione del ministro della salute al parlamento sugli interveniti, Realizzati ai sensi della legge 30.03.2001 N. 125. Legge Quadro in materia di alcol e problemi alcolcorrelat [online database]. Avaiable at: www.droganews.org/ pubdownload.php?id $=2271 \&$ ep $=53$ [accessed 01.03.2011]

Koehnke, M. D. (2008). Approach to the genetics of alcoholism: a review based on pathophysiology. Biochem. Pharmacol. 75, 160-177.

Kogoj, D., Lesch, O. M., Blüml, V., Riegler, A., Vyssoki, B., Schlaff, G., and Walter, H. (2010). Lesch Alcoholism Typology. Medical Treatment and Research. Arch. Psychiatr. Psychother. 4, 37-48.

Kubička, L., and Csémy, L. (2004). Analýza sociodemografického kontextu požívání alkoholických nápojův dospělé populace české republiky z hlediska zdravotního. Časopis lékařu českúch 143, 435-439.

Kubićka, L., and Csémy, L. (2008). Women's gender role orientation predicts their drinking patterns: a followup study of Czech women. Addiction 103, 929-937.

Lesch, O. M., Walter, H., Wetschka, C. H., Hesselbrock, M., and Hesselbrock, V. (2011). Alcohol and Tobacco, Medical and Sociological Aspects of Use, Abuse and Addiction. New York: Springer Wien.

Mclellan, T. (2010). National Drug Control Strategy, Written Statement [Online Database]. Available at: http://www.whitehousedrugpolicy.gov/news/ testimony10/06232010_dom_policy.pdf [accessed 01.03.2011].

Miller, W. R., Yahne, C. E., and Tonigan, J. S. (2003) Motivational interviewing in drug abuse services: a randomized trial. J. Consult. Clin. Psychol. 71, 754-763.

Mravčíkv, Pesek, R., Skarupová, K., Orliková, B. Skrdlantova, E., Stastna, L., Kissova, L., Belackova, V., Gajdosikova, H., and Vopravil, J. (2009). Annual Report: The Czech Republic - 2008 Drug Situation. Praha: Urad vlady Ceské republiky.

NIAAA. (2008). Alcohol Alert, July 2008 [Online Database] Available at: http://pubs.niaaa.nih.gov/publications/ aa76/aa76.htm [accessed 29.09.2011].
NMSAT. (2010). National Monitoring Center for Alcohol and Tobacco [Online Database]. Praha, Státní zdravotní ústav. Available at: http://www.szu.cz/tema/ podpora-zdravi/narodni-monitorovaci-strediskopro-alkohol-a-tabak?highlightWords = alkohol [accessed 27.08.2010].

Pitsavos, C., Panagiotakos, D. B., Chrysohoou, C., and Stefanadis, C. (2003). Epidemiology of cardiovascular risk factors in Greece: aims, design and baseline characteristics of the Attica study. BMC Public Health 20, 32. doi: 10.1186/1471-2458-3-32

Pombo, S., and Lesch, O. M. (2009). The alcoholic phenotypes among different multidimensional typologies: similarities and their classification procedures. Alcohol Alcohol 44, 46-54.

Rehm, J., and Scafato, E. (2011). Indicators of alcohol consumption and attributable harm for monitoring and surveillance in European Union countries. Addiction 106(Suppl. 1), 4-10.

Scafato, E. (2008). Alcol: epidemiologia e prevenzione in unaprospettiva evidence-based di tuteladella salute. ADI Magazine 4, 497-499.

Sovinova, H., and Csémy, L. (2010). The Czech AUDIT: Internal consistency, latent structure, and identification of risky alcohol consumption. Cent. Eur. J. Public Health 18, 127-131.

Vyssoki, B., Steindl-Munda, P., Ferenci, P., Walter, H., Höfer, P., Blüml, V., Friedrich, F., Kogoj, D., and Lesch, O. M. (2010). Comparison of alcohol dependent patients at an internal and a psychiatric ward according to the Lesch alcoholism typology - Implications for treatment. Alcohol Alcohol 45, 534-540.

WHO. (2004). Global Status Report on Alcohol [Online Database]. Available at: www.who.int/substance abuse/publications/global_status_report_2004_overview.pdf [accessed 01.03.2011].

WHO. (2010). European Status Report on Alcohol and Health 2010 [Online Database]. Copenhagen: WHO Regional Office for Europe. Available at: http://www. euro.who.int/_data/assets/pdf file/0004/128065/ e94533.pdf [accessed 01.03.2011].

WHO. (2002). WHO Global InfoBase [Online Database]. Available at: http://apps.who.int/infobase/Indicators. aspx [accessed 01.03.2011].

Received:22 July 2011; accepted:03 October 2011; published online: 01 November 2011.

Citation: Kogoj D, Addolorato G, Ferrulli A, Mouzas I, Okruhlica L, Poldrugo FA, Schlaff G, Zima T, Lesch O and Walter H (2011) Alpe Adria report 2010 - conclusions and recommendations for the treatment of alcohol dependence. Front. Psychiatry 2:58. doi: 10.3389/fpsyt.2011.00058

This article was submitted to Frontiers in Addictive Disorders, a specialty of Frontiers in Psychiatry.

Copyright (c) 2011 Kogoj, Addolorato, Ferrulli, Mouzas, Okruhlica, Poldrugo, Schlaff, Zima, Lesch and Walter. This is an open-access article subject to a non-exclusive license between the authors and Frontiers Media SA, which permits use, distribution and reproduction in other forums, provided the original authors and source are credited and other Frontiers conditions are complied with. 